Review Article

\title{
Diabetic Osteoporosis: A Review of Its Traditional Chinese Medicinal Use and Clinical and Preclinical Research
}

\author{
Rufeng Ma, ${ }^{1}$ Ruyuan Zhu, ${ }^{1}$ Lili Wang, ${ }^{1}$ Yubo Guo, ${ }^{1}$ Chenyue Liu, ${ }^{2}$ Haixia Liu, ${ }^{1}$ \\ Fengwei Liu, ${ }^{3}$ Hongjun $\mathrm{Li}^{,}{ }^{3} \mathrm{Yu} \mathrm{Li},{ }^{1}{ }^{\mathrm{Min}} \mathrm{Fu},{ }^{4}$ and Dongwei $\mathrm{Zhang}^{5}$ \\ ${ }^{1}$ Preclinical Medicine School, Beijing University of Chinese Medicine, Beijing 100029, China \\ ${ }^{2}$ Chinese Materia Medica School, Beijing University of Chinese Medicine, Beijing 100029, China \\ ${ }^{3}$ Henan Luoyang Orthopedic Traumatological Hospital, Luoyang 471000, China \\ ${ }^{4}$ The Research Institute of McGill University Health Center, Montreal, QC, Canada H4A $3 J 1$ \\ ${ }^{5}$ Diabetes Research Center, Beijing University of Chinese Medicine, Beijing 100029, China \\ Correspondence should be addressed to Dongwei Zhang; dongwei1006@gmail.com
}

Received 3 April 2016; Revised 15 July 2016; Accepted 18 July 2016

Academic Editor: Khalid Rahman

Copyright (c) 2016 Rufeng Ma et al. This is an open access article distributed under the Creative Commons Attribution License, which permits unrestricted use, distribution, and reproduction in any medium, provided the original work is properly cited.

\begin{abstract}
Aim. The incidence of diabetic osteoporosis (DOP) is increasing due to lack of effective management over the past few decades. This review aims to summarize traditional Chinese medicine (TCM) suitability in the pathogenesis and clinical and preclinical management of DOP. Methods. Literature sources used were from Medline (Pubmed), CNKI (China Knowledge Resource Integrated Database), and CSTJ (China Science and Technology Journal Database) online databases. For the consultation, keywords such as diabetic osteoporosis (DOP), TCM, clinical study, animal experiment, toxicity, and research progress were used in various combinations. Around 100 research papers and reviews were visited. Results. Liver-spleen-kidney insufficiency may result in development of DOP. 18 clinical trials are identified to use TCM compound prescriptions for management of patients with DOP. TCM herbs and their active ingredients are effective in preventing the development of DOP in streptozotocin (STZ) and alloxan as well as STZ combined with ovariectomy insulted rats. Among them, most frequently used TCM herbs in clinical trials are Radix Astragali, Radix et Rhizoma Salviae Miltiorrhizae, Radix Rehmanniae Preparata, and Herba Epimedii. Some of TCM herbs also exhibit toxicities in clinical and preclinical research. Conclusions. TCM herbs may act as the novel sources of anti-DOP drugs by improving bone and glucolipid metabolisms. However, the pathogenesis of DOP and the material base of TCM herbs still merit further study.
\end{abstract}

\section{Introduction}

Diabetic osteoporosis (DOP) is a chronic bone metabolic disease induced by diabetes mellitus (DM), and its pathogenesis involves an increase in osteoclast activity, a decrease in osteoblast activity, aggravation of bone microcirculation, an increase in adipogenic differentiation of mesenchymal multipotential stem cells (MMSCs), and an increase in advanced glycation end products (AGEs) $[1,2]$. With the increasing incidence of $\mathrm{DM}$ in the world, the number of patients with DOP increased accordingly [3]. Clinical studies have shown that about $1 / 2$ to $2 / 3$ of diabetic patients suffered from decreasing bone strength and/or increasing incidence of fractures, of whom nearly $1 / 3$ were diagnosed as osteoporosis
[4]. In recent years, traditional Chinese medicine (TCM) has attracted increasing attention in prevention and treatment of DOP. This review highlights the pathogenetical, clinical, and experimental advances in management of DOP in TCM and also provides a strong scientific evidence for understanding and improving the treatment of DOP.

\section{DOP Pathogenesis in TCM}

DOP belongs to the secondary osteoporosis, whose concept was first proposed in 1948 [2, 46]. In TCM, there is no corresponding term to describe DOP. However, the clinical performances are similar to the TCM symptoms of "atrophic debility of bones," "Gubi," "dryness of bone," or "pain in waist 
and lower extremities" [47]. According to TCM theories and clinical symptoms of DOP, the etiology of DOP is mainly attributed to the insufficiency of the spleen, liver, and kidney. In traditional Chinese physiology, the spleen (as is well known, all the organs in TCM bear the least resemblance to its western counterpart) is assumed to be responsible for assimilation of nutrients and maintenance of physical strength. The spleen governs blood, digestion, transformation, and transportation in the body [48]. So the spleen has the ability of transforming food into $Q i$ and blood and transporting them throughout the body. Proper functioning of the organ is essential to maintain muscle mass and strengthen limbs. Also, in traditional Chinese physiology, the liver ( $G a n$ ) stores blood, ensures the smooth flow of $Q i$, and controls the action and nutrition of tendon [49]. And the kidney (Shen) stores essence and controls the growth and development of bone $[50,51]$. Meanwhile, $Q i$ (Qi is the term used in TCM to describe the body's vital life energy [52]) deficiency and blood stasis also contributed to the development of DOP.

$X i a o-K e$ is an official terminology for diabetes in TCM [53]. TCM believes that Xiao-Ke mainly resulted from the dysfunctions of kidney, spleen, and liver [54]. As kidney controls bone growth and development via neuroendocrineimmune network and osteoclast regulatory pathway osteoprotegerin- (OPG-) receptor activator of nuclear factor kappa-B ligand- (RANKL-) RANK [51, 55], the deficiency of the kidney caused by Xiao-Ke further results in bone malnutrition. The liver dredges and smooths the route of something and produces blood by promoting circulation of blood and metabolism of body fluid and assisting the spleen and the stomach to digest food (http:// old.tcmwiki.com/wiki/the-liver). The loss of liver Yin in the development of Xiao-Ke causes blood deficiency, which leads to blood stasis, tendon, and vessels undernutrition [56]. The spleen has the function to transport and transform nutrients by digesting food, absorbing nutrients of food and water, and then transporting them to the heart and the lung (http://old.tcmwiki.com/wiki/the-spleen). If the essence transportation and transformation fails in spleen, dampness and circulation disorders of $Q i$ and blood will occur to the body [57]. Further, the bone is loss of nutrition which may cause insufficiency of bone marrow and bone pain [58]. The codysfunctions of liver, spleen, and kidney lead to $Q i$ deficiency and blood stasis, which further contributes to insufficiency of blood and essence [57, 59]. All the abnormalities lead to bone lesions and occurrence of DOP. The views on the pathogenesis of DOP have been also discussed in the ancient Chinese medicine works, such as "Inner Canon of Huangdi," "Clinic Guideline of Medical Records," and "Xue Zheng Lun." Therefore, prevention and treatment of DOP should focus on regulation and tonification of the liver, spleen, and kidney. The proper function of liver, spleen, and kidney promotes $Q i$ to disperse stagnation and reinforce kidney to replenish Yin, which beneficially contributes to improving bone metabolism.

In recent years, great achievements have been made in prevention and treatment of DOP in TCM. The results have demonstrated that TCM herbs not only had the abilities of increasing the bone quality by enhancing the mechanical strength of bone but also exhibited the effect on improving the primary disease by regulating glycaemia metabolism. Next, we review the clinical and preclinical research advances of using TCM in the treatment of DOP.

\section{Clinical Advances of DOP in TCM}

As mentioned previously, the clinical guidelines for TCM treatment of DOP are tonifying liver, spleen, and kidney as well as promoting $Q i$ flow and removing blood stasis. We summarized the TCM compound prescriptions used in the clinical trials of DOP as shown in Table 1. Till now, there are around 18 TCM prescriptions that have been used in managing patients with DOP, in which clinical studies have been performed by different investigators with various prescriptions. Zhang et al. [5] found that Tanggukang treatment reduced serum malondialdehyde (MDA) and blood glucose and increased the activity of superoxide dismutase (SOD) that contributed to controlling the glycaemia and suppressing osteoporosis in patients with DOP. In addition, both Tanggukang [6] and Qianggubao granule treatments also had significant effects on patients with DOP evidenced by improving calcium and phosphorus metabolism and hydroxyproline level as well. In addition, Ji et al. [7] found that Bushen Huoxue decoction treatment not only controlled glycaemia and lipidemia but also obviously improved bone mineral density (BMD) in patients with DOP. Shang et al. $[8,9]$ found that Bushen Tongluo decoction had the ability of improving BMD and reducing the risk of bone fractures in patients with DOP. Gong and Li [10] found that Jiawei Qinge pill treatment improved DOP patients in blood glycosylated hemoglobin (HbAlC), calcium and phosphorus level, and fasting urine $\mathrm{Ca} /$ creatine ratio which beneficially contributed to the balance of bone metabolism. Yushanjiang and Halida [11] showed that the Xihongkang treatment prevented the development of DOP by tonifying $Q i$, nourishing Yin, and promoting blood circulation. Deng [12] demonstrated that Yishen Zhuanggu decoction treatment increased serum bone gla-protein (BGP) and $1,25-(\mathrm{OH})_{2} \mathrm{D}_{3}$ levels and $\mathrm{BMD}$ value in patients with DOP.

Furthermore, treatments with TCM formulas, such as Huqian pills [13], Gusong decoction [14, 15], Tangmaikang granules [16], Bushen Huoxue decoction [17], Jiawei Gutongxian capsule [18], Qianggubao granule [19], Jiangu decoction [20], Jiangtang Bushen formulation [21], Huolisu oral liquid [22], Migu decoction [23], and Xianling Gubao [24], have also been demonstrated to improve BMD, decrease serum C-reactive protein (CRP) level, and attenuate lumbar pain evidenced by decreasing visual analogue scale pain score in vertebra and back in the patients with DOP.

Most of prescriptions used in management of DOP consist of 4 to 14 herbs. Eight of most appearing Chinese herbs in the clinical studies are compiled in Table 2. All of these herbs possess the functions of invigorating $Q i$, activating blood circulation, and replenishing vital essence to tonify kidney [60]. The applications also conform to the TCM pathogenesis of DOP. The prescriptions are helpful for the investigators to screen the active ingredients against DOP from these herbs in the future. 


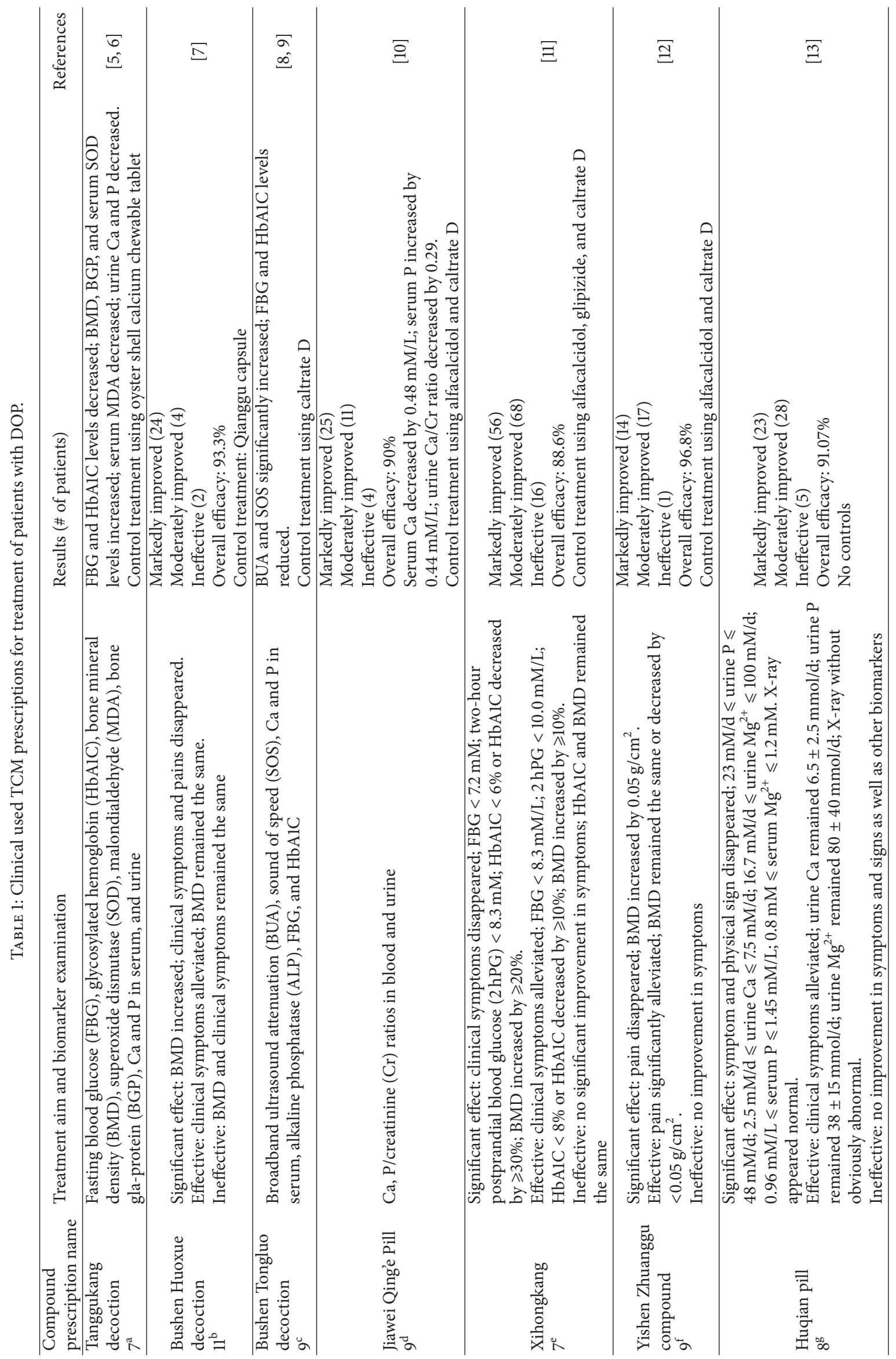




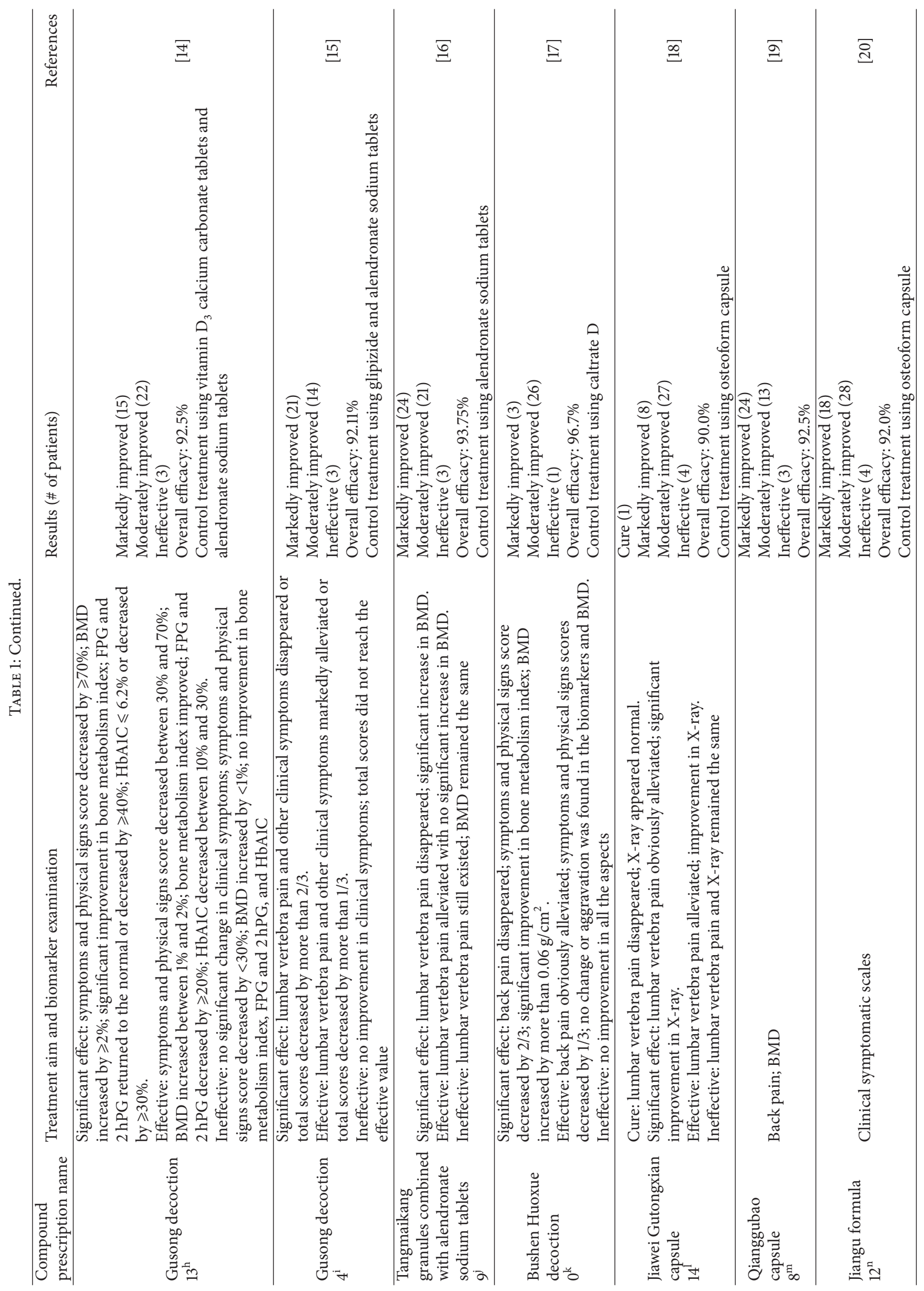




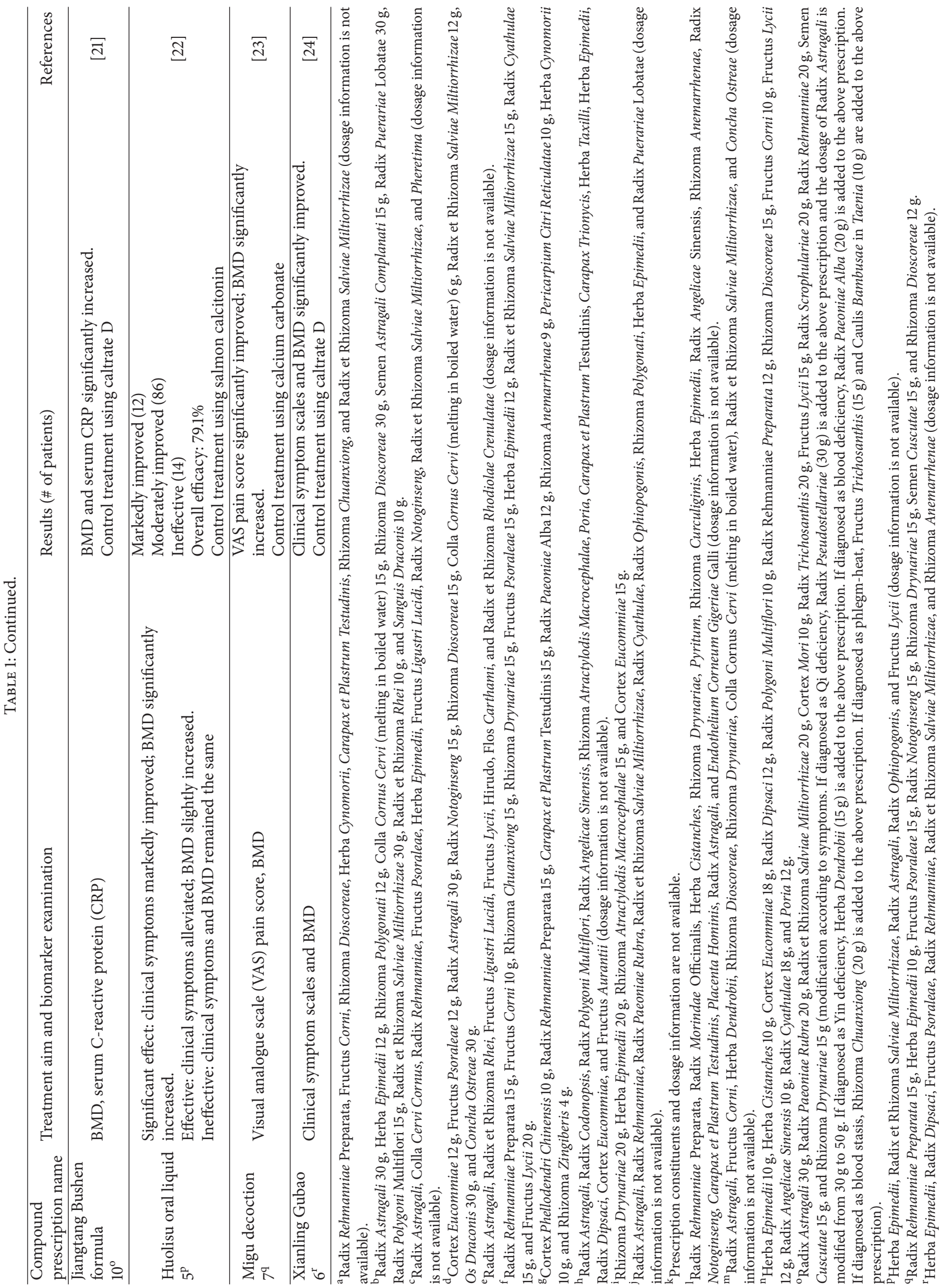


TABLE 2: Medicinal herbs most frequently used in clinical trials of DOP.

\begin{tabular}{lc}
\hline Name of herb & Frequency \\
\hline Radix Astragali & 11 \\
Herba Epimedii & 10 \\
Radix et Rhizoma Salviae Miltiorrhizae & 10 \\
Radix Rehmanniae Preparata & 6 \\
Rhizoma Drynariae & 6 \\
Fructus Lycii & 5 \\
Cortex Eucommiae & 4 \\
Rhizoma Dioscoreae & 4 \\
\hline
\end{tabular}

Based on the listed prescriptions from Table 1, it is found that TCM treatments improved DOP through multichannel and different levels in the clinical trials. And the most commonly used herbs are Radix Astragali, Radix et Rhizoma Salviae Miltiorrhizae, Herba Epimedii, and Radix Rehmanniae Preparata. These four herbs have also been well evidenced to play a beneficial role in the treatment of diabetes by inhibiting AGEs formation [61], improving mitochondrial function and biogenesis, interfering with cell cycle [62], increasing insulin sensitivity and glycogen synthesis [6365], and improving $5^{\prime}$ adenosine monophosphate-activated protein kinase signaling $[66,67]$ as well as regulating tissue regeneration and angiogenesis to promote diabetic foot ulcer healing [68]. Meanwhile, these four herbs were also demonstrated to exhibit antiosteoporotic effect by inhibiting osteoclastogenesis and promoting osteoblastogenesis through regulating mitogen-activated protein kinase [69], Wnt/ $\beta$-catenin, bone morphogenetic proteins/SMAD, and OPG/RANKL/cathepsin K/nuclear factor kappa-B (NF- $\kappa \mathrm{B})$ signaling $[26,70,71]$.

However, the current clinical studies are limited to small scale of samples and regional hospitals. Meanwhile, the clinical trials do not fully conform to the rule of randomized, double-blind, and parallel group which markedly impacted the correct evaluation of clinical research results. In addition, clinical observation indexes are limited more in BMD than in bone strength and fracture incidence. The stability and repeatability of the compound preparations used in clinical trials also remain open and should be studied further. Therefore, the credibility of the results needs to be further improved. So it is not conducive to developing standardized diagnosis method and treatment program as well as the development of new drugs.

\section{Preclinical Advances of DOP in TCM}

4.1. The Applications of Single Chinese Herbs in the Treatment of DOP in Animal Experiments. Single herbs or their extracts have been extensively studied in the DOP animal models (Table 3). In an experiment performed by Zhang et al., the water fraction of Fructus Ligustri Lucidi (FLL) ethanol extract (WF-EE, $574 \mathrm{mg} / \mathrm{kg}$, i.g.) has been demonstrated to improve the trabecular bone deteriorations and inhibit hypercalciuria and increase serum parathyroid hormone (PTH) and fibroblast growth factor-23 in streptozotocin (STZ, $40 \mathrm{mg} / \mathrm{kg}$ ) induced DBA/2J mice [25]. The underlying mechanism of WF-EE treatment may be attributed to increase of gene expressions of transient receptor potential vanilloid (TRPV) and calcium binding protein $9 \mathrm{~K}$ (CaBP$9 \mathrm{~K}$ ) in duodenum in DOP mice. Further, using alloxan $(200 \mathrm{mg} / \mathrm{kg}$ ) induced diabetic rats, Radix et Rhizoma Salviae Miltiorrhizae treatment ( $5 \mathrm{~g} / \mathrm{kg}$ for 8 weeks) [26, 27] significantly improved serum calcium, alkaline phosphatase (ALP), BGP, and tartrate-resistant acid phosphatase levels and increased BMD value in alveolar bone osteoporosis. In addition, treatment with tetramethylpyrazine $(100 \mathrm{mg} / \mathrm{kg}$ for 15 weeks, the active ingredients isolated from Rhizoma Chuanxiong) [28] markedly increased bone hydroxyproline and collagen levels in streptozotocin (STZ, $60 \mathrm{mg} / \mathrm{kg}$ ) induced diabetic rats. Treatment with the alcohol extracts of Eucommia ulmoides Oliv. leaves [29] (6 g/kg) improved serum estradiol and increased BMD values in STZ (50 mg/kg) induced diabetic and ovariectomized (OVX) rats. Fructus Ligustri Lucidi [72], Rhizoma Chuanxiong [73], the leaves of Eucommia ulmoides Oliv. [74], and Radix et Rhizoma Salviae Miltiorrhizae [75] have been demonstrated with the function of tonifying kidney and promoting blood circulation.

Treatment with puerarin, the active substance isolated from Radix Puerariae with the function of improving blood circulation [76], significantly increased ALP level $(40 \mu \mathrm{M}$ for 48 hours, i.p.) [77], decreased expression of caspase-3 in osteoblasts ( $80 \mathrm{mg} / \mathrm{kg} /$ day for 6 weeks; i.p.) [30], and reduced blood glucose and improved empty lacunar and BMD (100 mg/kg for 6 weeks, i.p. [31]) in STZ (65 mg/kg) induced diabetic rats. The results suggest that puerarin promotes osteoblast proliferation and inhibits osteoclast activation.

Aralia echinocaulis Hand-Mazz has been documented to distribute to kidney channel based on TCM theories [78]. The flavonoids isolated from the Aralia echinocaulis HandMazz treatment $(20 \mathrm{mg} / \mathrm{kg})$ [32] significantly improved the bone metabolism evidenced by increasing BMD value, bone strength, and bone mineral content in STZ $(30 \mathrm{mg} / \mathrm{kg})$ insulted male rats. In addition, the aqueous extract of Aralia echinocaulis Hand-Mazz (3.6 g/kg for 14 days) was evidenced to promote the expressions of fibroblast growth factor receptor 2, Fms-like tyrosine kinase, and fetal liver kinase which contributed to promoting angiogenesis and osteoblastogenesis in fracture healing model rats [78].

Treatment with quercetin increased serum osteocalcin, ALP, and urinary deoxypyridinoline (quercetin at $5 \mathrm{mg} / \mathrm{kg}$ showed little effect, while quercetin at $30 \mathrm{mg} / \mathrm{kg}$ and $50 \mathrm{mg} / \mathrm{kg}$ exhibited good effects for 8 weeks) in STZ induced diabetic osteopenia in rats [33]. The beneficial effect of quercetin also reflected on partially reversing the decreased biomechanical quality and improving microarchitecture of the femurs in the diabetic rats. The underlying mechanism may be due to its antioxidant capability. In addition, quercetin was also demonstrated to have a protective role in reducing $\beta$-cell damage and decreasing glycaemia in diabetic rats [79]. Furthermore, quercetin is widely embraced in TCM herbs and possessed the function of improving blood circulation $[80,81]$. 
TABLE 3: Single herb or herbal extracts used in the treatment of DOP animals.

\begin{tabular}{|c|c|c|c|c|}
\hline TCM name & Active constituents & Animal model & $\begin{array}{l}\text { Administration route, } \\
\text { duration, and dosage }\end{array}$ & Reference \\
\hline Fructus Ligustri Lucidi & $\begin{array}{l}\text { Water fraction of Fructus } \\
\text { Ligustri Lucidi ethanol } \\
\text { extract }\end{array}$ & STZ (40 mg/Kg) & $\begin{array}{c}\text { Intragastric administration } \\
\text { (i.g.) }(574 \mathrm{mg} / \mathrm{kg}) \text { for } 6 \\
\text { weeks }\end{array}$ & {$[25]$} \\
\hline $\begin{array}{l}\text { Radix et Rhizoma Salvia } \\
\text { miltiorrhiza }\end{array}$ & 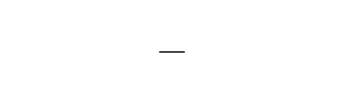 & $\begin{array}{c}\text { Alloxan } \\
(200 \mathrm{mg} / \mathrm{kg})\end{array}$ & i.g. $(5 \mathrm{~g} / \mathrm{kg})$ for 8 weeks & {$[26,27]$} \\
\hline Rhizoma Chuanxiong & Tetramethylpyrazine & $\mathrm{STZ}(60 \mathrm{mg} / \mathrm{Kg})$ & i.g. $(100 \mathrm{mg} / \mathrm{kg})$ for 15 weeks & {$[28]$} \\
\hline Cortex Eucommiae & $\begin{array}{c}\text { Ethanol extracts of } \\
\text { Eucommia ulmoides Oliv. } \\
\text { leaves }\end{array}$ & $\begin{array}{l}\text { STZ combined } \\
\text { with OVX }\end{array}$ & i.g. $(6 \mathrm{~g} / \mathrm{kg})$ for 8 weeks & {$[29]$} \\
\hline Radix Puerariae & Puerarin & $\mathrm{STZ}(65 \mathrm{mg} / \mathrm{Kg})$ & i.g. $(100 \mathrm{mg} / \mathrm{kg})$ for 6 weeks & {$[30,31]$} \\
\hline $\begin{array}{l}\text { Aralia echinocaulis } \\
\text { Hand-Mazz }\end{array}$ & $\begin{array}{l}\text { The flavonesof Aralia } \\
\text { echinocaulis Hand-Mazz }\end{array}$ & $\mathrm{STZ}(30 \mathrm{mg} / \mathrm{kg})$ & i.g. $(20 \mathrm{mg} / \mathrm{kg})$ for 6 weeks & {$[32]$} \\
\hline- & Quercetin & STZ & $\begin{array}{l}\text { i.g. }(5,30 \text { and, } 50 \mathrm{mg} / \mathrm{kg}) \\
\text { for } 8 \text { weeks }\end{array}$ & {$[33]$} \\
\hline Vitis vinifera L. seeds & - & $\mathrm{STZ}(60 \mathrm{mg} / \mathrm{kg})$ & $\begin{array}{l}\text { i.g ( } 0.028 \mathrm{mg} / \mathrm{kg} \text { every } \\
\text { other day) for } 16 \text { weeks }\end{array}$ & {$[34]$} \\
\hline Nigella sativa L. & Thymoquinone & $\mathrm{STZ}(50 \mathrm{mg} / \mathrm{kg})$ & i.g. $(2 \mathrm{~mL} / \mathrm{kg})$ for 4 weeks & {$[35-38]$} \\
\hline
\end{tabular}

Note: "-" denotes that the content was not clearly stated in the cited reference.

The combination treatments with polyphenols extracted from the seeds of Vitis vinifera L. $(0.028 \mathrm{mg} / \mathrm{kg}$, every two days for 16 weeks) [34] and the fruits of Sambucus nigra L. $(0.04 \mathrm{~g} / \mathrm{kg}$, every two days for 16 weeks) $[35,36]$ statistically improved BMD in STZ induced diabetic rats. Further, the combination treatments with Nigella sativa L. and parathormone $[36,37]$ have also been demonstrated to improve the bone strength in diabetic rats.

Taken together, the herbs used in the treatment of DOP animals usually have the functions of nourishing Yin and tonifying kidney, promoting blood circulation, which have been demonstrated to possess the ability of improving the bone metabolism in DOP $[76,82]$. The most accepted pharmacologically active ingredients of these herbs are flavonoids, polyphenols, alkaloids, polysaccharides, and so forth.

4.2. The Advances of TCM Compounds in the Treatment of DOP in Animal Experiments. As is well known, TCM compounds are composed of 2 or more Chinese drugs, which may play a synergistic action during the treatment of diseases. An experiment performed by Du et al. [39] demonstrated that Bushen Zhuanggu capsule (16 and $32 \mathrm{~g} / \mathrm{kg}$ ) treatment not only decreased blood glucose but also increased bone calcium and phosphorus as well as bone minerals in alloxan $(120 \mathrm{mg} / \mathrm{kg})$ induced diabetic rats. Jiang et al. [40] also found that Shenxiaokang concentrated pill (modified from Bawei Shenqi pill) treatment increased the thickness of bone epiphysis and improved trabecular nesh structure in STZ $(25 \mathrm{mg} / \mathrm{kg})$ induced diabetic male rats. One formula named Bushen Jianpi Huoxue decoction [41] was also evidenced to significantly reduce blood glucose, phosphorus, and ALP level and improve insulin resistance as well as increase BMD value in high fat diet and STZ $(30 \mathrm{mg} / \mathrm{kg})$ induced rats.
In addition, Shuanghuang Yigu formula treatment [42] significantly reduced blood glucose and urine desoxypyirdoxine levels and increased blood BGP level in ovariectomized rat with STZ $(50 \mathrm{mg} / \mathrm{kg})$ injection.

Emerging formulas have been demonstrated to play a beneficial role in management of DOP animals. Tangshukang [43], one formula invented by Guan et al., was demonstrated to improve calcium and phosphorus metabolism, increase BGP level, and reduce bone ALP level in STZ $(60 \mathrm{mg} / \mathrm{kg})$ induced diabetic osteoporosis rats. The underlying mechanism may be attributed to improve mRNA levels of vitamin $\mathrm{D}$ receptor and $\mathrm{CBP} 9 \mathrm{~K}$ in the small intestine and increase mRNA level of transforming growth factor- (TGF-) $\beta 1$ in the bone [83].

Furthermore, Bushen Zhuanggu capsule [44] treatment improved blood glucose metabolism through regulating insulin secretion, promoting bone TGF- $\beta 1$ expression and inhibiting caspase- 3 expression in osteoblast, and modulating the metabolic disorder of calcium-regulating hormones such as PTH, calcitonin, and vitamin D3 in alloxan (i.p. of $120 \mathrm{mg} / \mathrm{kg}$, twice every other day) induced diabetic rats.

In addition, Qianggubao treatment [45] reduced the expressions of interleukin-6 (IL-6), tumor necrosis factor alpha (TNF- $\alpha$ ), and carboxyterminal cross-linked telopeptide of type I collagen (ICTP) and increased IGF-1 and carboxyterminal propeptide of type I procollagen (PICP) production in alloxan (i.p. of $120 \mathrm{mg} / \mathrm{kg}$, twice every other day) induced diabetic osteoporosis rats. Further, Qianggubao [84] treatment also inhibited the formation of AGEs which was unfavorable for bone formation [85].

Most of formulas used in management of DOP not only have the function of improving bone metabolism but also afford effects on regulating glucose metabolism. However, as shown in Table 4, the ingredients of the formulas are 
TABLE 4: TCM prescriptions in the treatment of DOP animals.

\begin{tabular}{|c|c|c|c|}
\hline $\begin{array}{l}\text { TCM compound prescription } \\
\text { name }\end{array}$ & Animal model & $\begin{array}{l}\text { Administration route, duration, } \\
\text { and dosage }\end{array}$ & Reference \\
\hline $\begin{array}{l}\text { Bushen Zhuanggu capsule } \\
2^{\mathrm{a}}\end{array}$ & $\begin{array}{c}\text { Alloxan }(120 \mathrm{mg} / \mathrm{kg} \text {, twice every } \\
\text { other day) }\end{array}$ & i.g. $(8,16$ and $32 \mathrm{~g} / \mathrm{kg})$ for 8 weeks & {$[39]$} \\
\hline $\begin{array}{l}\text { Shenxiaokang concentrated pill } \\
9^{\mathrm{b}}\end{array}$ & $\begin{array}{c}\mathrm{STZ}(25 \mathrm{mg} / \mathrm{kg}) \text {, once a day for } 5 \\
\text { days }\end{array}$ & i.g. $(1.58 \mathrm{~g} / 200 \mathrm{~g})$ for 7 weeks & {$[40]$} \\
\hline $\begin{array}{l}\text { Bushen Jianpi Huoxue decoction } \\
8^{c}\end{array}$ & $\begin{array}{l}\text { high fat diet for } 4 \text { weeks, i.p. of } \\
\text { STZ (30 mg/kg) }\end{array}$ & i.g. $(15 \mathrm{~g} / \mathrm{kg})$ for 12 weeks & [41] \\
\hline $\begin{array}{l}\text { Shuanghuang Yigu formula } \\
9^{\mathrm{d}}\end{array}$ & $\begin{array}{c}\text { i.p. of STZ }(50 \mathrm{mg} / \mathrm{kg}) \text { combined } \\
\text { with OVX }\end{array}$ & i.g. $(11.5 \mathrm{~g} / \mathrm{kg})$ for 10 weeks & {$[42]$} \\
\hline $\begin{array}{l}\text { Tangshukang capsule } \\
0^{\mathrm{e}}\end{array}$ & i.p. of STZ (60 mg/kg) & i.g. $(15 \mathrm{~g} / \mathrm{kg})$ for 12 weeks & {$[43]$} \\
\hline $\begin{array}{l}\text { Bushen Zhuanggu capsule } \\
0^{\mathrm{f}}\end{array}$ & $\begin{array}{c}\text { i.p. of alloxan }(120 \mathrm{mg} / \mathrm{kg} \text {, twice } \\
\text { every other day })\end{array}$ & i.g $(8,16$ and $32 \mathrm{~g} / \mathrm{kg})$ for 7 weeks & {$[44]$} \\
\hline $\begin{array}{l}\text { Qianggubao } \\
10^{\mathrm{g}}\end{array}$ & $\begin{array}{c}\text { i.p. of alloxan }(120 \mathrm{mg} / \mathrm{kg} \text {, twice } \\
\text { every other day) }\end{array}$ & i.g $(1 \mathrm{~mL} / 100 \mathrm{~g})$ for 12 weeks & {$[45]$} \\
\hline \multicolumn{4}{|c|}{$\begin{array}{l}\text { badix Rehmanniae Preparata, Rhizoma Dioscoreae, Fructus Corni, Poria, Rhizoma Alismatis, Pericarpium Citri Reticulatae, Radix Astragali, and Hirudo } \\
\text { (dosage information is not available). } \\
{ }^{\mathrm{c}} \text { Radix Rehmanniae Preparata, Cortex Eucommiae, Radix Astragali, Fructus Lycii, Colla Cornus Cervi (melting in boiled water), Radix et Rhizoma Salviae } \\
\text { Miltiorrhizae, Rhizoma Anemarrhenae, and Radix Cyathulae (dosage information is not available). }\end{array}$} \\
\hline \multicolumn{4}{|c|}{$\begin{array}{l}\text { 'Os Draconis, Radix Rehmanniae Preparata, Radix Astragali, Cortex Eucommiae, Radix Dipsaci, Rhizoma Drynariae, Fructus Lycii, Fructus Corni, Poria, Radix } \\
\text { Angelicae Sinensis, Radix Cyathulae, Herba Artemisiae Anomalae (dosage information is not available). } \\
\text { e TCM names and dosage information are not available. }\end{array}$} \\
\hline
\end{tabular}

not constant and fixable. And the commonly used TCM herbs also exhibit the effects of tonifying kidney, promoting blood circulation and removing blood stasis, which is also consistent with the main pathogenesis of DOP in TCM.

As is mentioned in Table 4, three types of DOP models are employed to evaluate the effect of TCM in the treatment of DOP, including STZ, alloxan, and STZ combined with OVX induced animal models. In addition, pigs are also used as the experimental DOP models [86].

\section{The Toxicity of the Herbs}

Toxicity is becoming a rising concern in the application of TCM in the clinical trials. Contrary to most of the modern toxicity data derived from animal experiments, the toxicities of TCM herbs in Chinese literature have been documented through clinical experiences. Before properly reviewing and studying the toxicities of the species by modern medical, pharmacological, and/or pharmaceutical sciences, the researchers must bear in mind that the isolated chemicals and the extracts from the herbs are not identical to the original herbs or formulas, while the traditional properties and indications of TCM herbs and formulas are the validated source of interpreting and extrapolating assessments of the toxicities. For knowing how to well understand the toxicities of TCM herbs, we suggest that the interested readers consult Dr. Leung's review [87].
In the above-mentioned species, several of them were evidenced to have toxicity issues for medicinal use. Nigella sativa L. extracts were demonstrated to possess the ability of lowering blood glucose in the healthy subjects. Therefore, caution must be excised when Nigella sativa L. extracts were applied to treat pregnant women, children, and diabetic patients [88]. For children, Nigella sativa L. at doses below $80 \mathrm{mg} / \mathrm{kg}$ was considered as safe dosages as there were no observed side effects being reported [89]. For detailed toxicity information of Nigella sativa L., we suggest that the readers consult Shuid et al.'s review [35].

It has been revealed that Pueraria tuberosa Linn. (Fabaceae) methanol extract of tubers showed LD50 at $227.5 \mathrm{mg}$ in acute study in rats. For subchronic study, repeated challenges (5-100 mg/100 g, for 30 days) dose-dependently increased hepatic enzymes in blood, inflammatory cell infiltration, and hepatocellular necrosis. Kinetic study (single dose at $227.5 \mathrm{mg} / 100 \mathrm{~g}$ ) revealed a decrease in GSH and an increase in free-radical generation [90, 91]. Puerarin, the major component of Radix Puerariae, has been demonstrated to cause hepatotoxicity as well as pathological changes in jejunum and spleen by high dose administration of puerarin freeze dried powder (100 and $200 \mathrm{mg} / \mathrm{kg}$ for 13 weeks, i.v.) to $\mathrm{SD}$ rats [92]. Interested readers are encouraged to consult Zhang et al.'s review [93].

The extracts of Radix Astragali, which consist of Astragalus polysaccharide and Astragalus membranaceus saponins, were evidenced safe without any distinct toxicity and side effects in the subchronic toxicity study. The safety dosage 


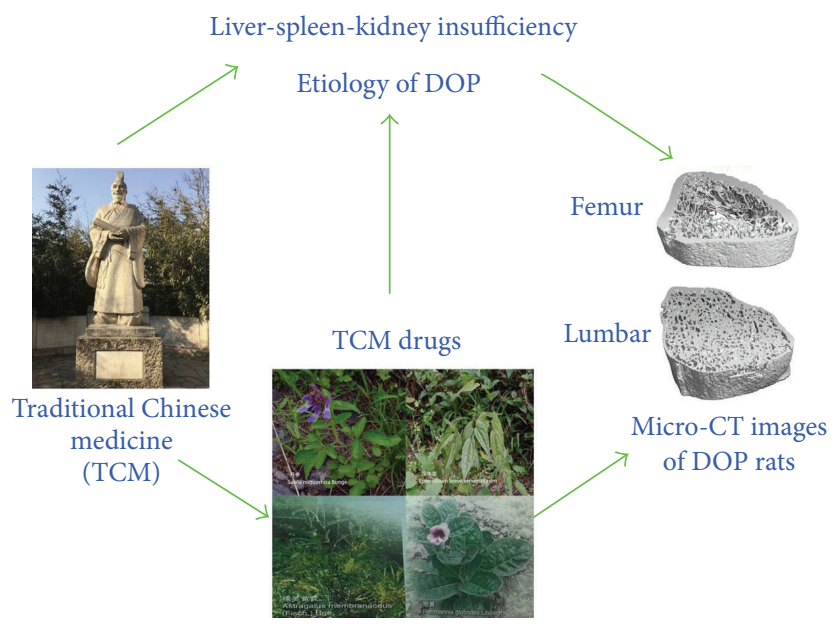

Scheme 1: Liver-spleen-kidney insufficiency is closely associated with the induction of DOP. The most commonly used TCM herbs for treatment of DOP are Radix Astragali, Radix et Rhizoma Salviae Miltiorrhizae, Radix Rehmanniae Preparata, and Herba Epimedii. These herbs are evidenced to improve the management of DOP in clinical and preclinical study.

range is $2.85-19.95 \mathrm{~g} / \mathrm{kg}$ for beagle dogs and $5.7-39.9 \mathrm{~g} / \mathrm{kg}$ for rats [94]. And so far, no clinical toxicity data were reported.

The major tanshinones (cryptotanshinone, tanshinone I, tanshinone IIA, and dihydrotanshinone) isolated from Salvia miltiorrhiza Bunge were observed to induce HepG2 cell apoptosis in vitro [95]. Flow cytometry results demonstrated that tanshinone IIA $(12.5$ and $25 \mu \mathrm{M})$ treatment increased fragmented DNA in HepG2 cells. Cryptotanshinone, tanshinone I, and dihydrotanshinone elevated GSH/GSSG ratio at low concentrations $(1.56$ and $3.13 \mu \mathrm{M})$ and decreased GSH/GSSG ratio at high concentrations $(6.25-25 \mu \mathrm{M})$, which indicates that these compounds may disturb redox balance in HepG2 cells. Another experiment performed by Xu et al. claimed that liposoluble components of Salvia miltiorrhiza Bunge $(\mathrm{IC} 50=2.181 \mu \mathrm{g} / \mathrm{mL})$ and tanshinone IIA (IC50 = $6.176 \mu \mathrm{g} / \mathrm{mL}$ ) inhibited proliferation of rat retinal Müller cell in vitro by CCK- 8 examination at $48 \mathrm{~h}$ [96]. But the authors did not show the cell viabilities at various time points which are useful to evaluate the drug toxicity.

Cortex Eucommiae is also widely used in the treatment of DOP. In chronic toxicity experiments in rats, the seeds and barks of Eucommia ulmoides Oliv. were found to affect the utilization rate of food, the routine blood and liver function, and the organ coefficient of the liver, spleen, testis, and ovary. But the investigators did not find abnormalities in histological examination. They also did not discover abnormalities in acute toxicity, bone marrow of mice micronuclear test, and sperm deformity experiments $[97,98]$.

\section{Conclusions and Remarks}

The clinical studies and basic research achievements support that TCM offers a new strategy in prevention and treatment of DOP (Scheme 1). TCM herbs and compounds have effects on resolving DOP through invigorating kidney $\mathrm{Q} i$, promoting blood circulation, and removing blood stasis.
This is consistent with TCM belief that liver-spleen-kidney insufficiency is closely associated with the induction of DOP. The most commonly used TCM herbs for treatment of DOP are Radix Astragali, Radix et Rhizoma Salviae Miltiorrhizae, Radix Rehmanniae Preparata, and Herba Epimedii. The investigators also demonstrate that these herbs have the beneficial effects on diabetes and osteoporosis. Three types of DOP models (STZ, alloxan, and STZ plus OVX induced animal disease models) are employed to evaluate the effect of TCM on DOP animals. These results clearly support that TCM herbs treatment not only improves bone metabolism but also prevents the development of diabetes. It is noticeable that some of TCM herbs and extracts may have the toxicities over the thresholds. Great care must be taken when TCM herbs are employed to treat DOP.

However, the basic research on single herbs and TCM compounds in the treatment of DOP is still very weak, and there is still a long way to find the mechanisms and active ingredients in TCM herbs. The researchers also need to pay attention that the pathogenesis of DOP is a multifaceted chronic metabolic disease, and a comprehensive study with multidisciplinary technology and comprehensive usage of various approaches should be employed to explore pathogenesis and to prevent the development of DOP. The further understanding of these concerns will contribute to providing a more scientific basis for management of DOP.

\section{Disclosure}

These funding agencies have no roles in study design; in data collection, analysis, and interpretation; in the writing of the report; and in the decision to submit the paper for publication.

\section{Competing Interests}

The authors declare that they have no competing interests. 


\section{Authors' Contributions}

Rufeng Ma, Ruyuan Zhu, and Lili Wang equally contributed to this work.

\section{Acknowledgments}

This work was supported by grants from National Natural Science Foundation of China (NSFC81274041 and NSFC81273995), International Cooperation projects of MOE (2011DFA30920), and Key Drug Development Program of MOST (20122X09103201-005) as well as the 111 project of MOE (B07007).

\section{References}

[1] S. Epstein, G. Defeudis, S. Manfrini et al., "Diabetes and disordered bone metabolism (diabetic osteodystrophy): time for recognition," Osteoporosis International, vol. 27, no. 6, pp. 19311951,1931

[2] W.-L. Zhang, H.-Z. Meng, and M.-W. Yang, "Regulation of DMT1 on bone microstructure in type 2 diabetes," International Journal of Medical Sciences, vol. 12, no. 5, pp. 441-449, 2015.

[3] B. Roy, "Biomolecular basis of the role of diabetes mellitus in osteoporosis and bone fractures," World Journal of Diabetes, vol. 4, no. 4, pp. 101-113, 2013.

[4] P. Piscitelli, C. Neglia, A. Vigilanza, and A. Colao, "Diabetes and bone: biological and environmental factors," Current Opinion in Endocrinology, Diabetes and Obesity, vol. 22, no. 6, pp. 439-445, 2015.

[5] Y. Zhang, W.-H. Yu, and X.-L. Wang, "Effects of Tanggukang on serum free radical metabolism in patients with diabetic osteoporosis," Journal of Clinical Rehabilitative Tissue Engineering Research, vol. 12, no. 7, pp. 1251-1254, 2008.

[6] W. H. Yu and Y. Zhang, "Effect of Tanggukang Decoction on the metabolism of calcium and phosphourous in the patients of diabetes with osteoporosis," Zhongguo Zhongyi Jizheng, vol. 18, no. 1, pp. 45-46, 2009.

[7] B. Ji, J. Guan, X. Chen et al., "Clinical research of self-made kidney-tonifying and blood circulation-promoting Chinese medicine in patients with diabetic osteoporosis," Guide of China Medicine, vol. 10, no. 17, pp. 3-4, 2012.

[8] X. Shang, S. Xu, Q. Zhou et al., "Clinical observations on the effect of Bushen Tongluo capsule for treatment of diabetic osteoporosis," China Pharmacist, vol. 13, no. 9, pp. 1329-1330, 2010.

[9] X. Shang, P. Xie, X. Guo, and T. Zhang, "The influence of Bushen Tongluo Compound on bone mineral density and balance ability of patients with diabetic osteoporosis," Captial Medicine, vol. 17, no. 16, pp. 60-61, 2010.

[10] Z. D. Gong and C. J. Li, "Clinical research of modified Qing'e pill on diabetic osteoporosis," Zhongguo Zhongyi Jizheng, vol. 21, no. 9, pp. 1391-1402, 2012.

[11] A. Yushanjiang and M. Halida, "Clinical study on effect of Xihongkang for the treatment diabetic osteoporosis," Chinese Journal of Basic Medicine in Traditional Chinese, vol. 18, no. 9, pp. 1001-1002, 2012.

[12] M. Deng, "Clinical studies on the effect of Yishen Zhuanggu Compound for the treatment of type 2 diabetes induced osteoporosis," Guiyang Journal of TCM College, vol. 35, no. 1, pp. 58-59, 2013.
[13] L. Zhang, "Clinical observation on 56 cases of patients with diabetic osteoporosis in using Huqian Pill," Hebei Journal of TCM, vol. 25, no. 3, p. 180, 2013.

[14] R. Liu, Observe the Safety and Efficacy of TCM Gu-Song Decoction to Diabetic Osteoporosis (DOP) Patients, Chengdu University of Chinese Medicine, Chengdu, China, 2013.

[15] C. Hao, "Clinical Study on the effect of Gusong decoction on patient with dibetic osteoporosis," Asia Pacific Traditional Medicine, vol. 11, no. 10, pp. 117-118, 2015.

[16] M. Gao, "Clinical observation of tangmaikang granules combined with alendronate sodium tablets in the treatment of bone metabolism in elderly patients with type 2 diabetes," China Pharmacy, vol. 23, no. 28, pp. 2658-2660, 2012.

[17] Z. Feng, X. Yue, F. Li, Y. Wei, and Z. Li, "Clinical study of the effect of Bushen Huoxue principle on bone metabolism of patients with daibetic osteoporosis," in Proceedings of the 14th TCM Diabtes Conference, Diabetes Sub-society of China Chinese Medicine Assocation, Zhengzhou, China, 2012.

[18] W. Jia, Z. Wu, and Q. Dong, "Clinical observation of the effect of Jiawei Gutongxian Capasule on the treatment of patients with diabetic osteoporosis," Hebei Journal of TCM, vol. 28, no. 11, pp. 822-823, 2006.

[19] Y. Su, S. Qian, Z. Dong, J. Guo, and A. Zhang, "Clinical observation on QIANGGUBAO for treating 40 cases of diabetic osteoporosis," Journal of Fujian College of TCM, vol. 11, no. 3, pp. 23-25, 2001.

[20] L. Zhao, "50 cases of clinical trials in the treatment of diabetic bone metabolism by self-made Jiangu decoction," Hei Long Jiang Journal of TCM, vol. 29, no. 1, p. 46, 2000.

[21] L. Huang, "Clinical study of the effect of Jiangtang Bushen formulation on bone mineral density and serum $\mathrm{C}$ reactive protein on patients with diabetic osteoporosis," Fujian Journal of TCM, vol. 40, no. 6, pp. 15-16, 2009.

[22] H. Shen, J. Huang, and Y. Wang, "Clinical observation of the effect of combination of huolisu oral liqiud and salmon calcitonin on the treatment of old patients with diabetic osteoporosis," Chinese Journal of Information on TCM, vol. 15, no. 1, pp. 78-79, 2009.

[23] F. Yan, Y. Zhang, and Z. Wang, "The effect of Migu decoction on the treatment of patients with type 2 diabetes osteoporosis," Hebei Medicinal Journal, vol. 34, no. 21, pp. 3340-3341, 2002.

[24] Y. You, R. Zhuang, H. Zhao, and Y. Xie, "Clinical therapeutical effect of xianling gubao on patients with diabetic osteoporosis," Journal of Pharmaceutical Research, vol. 33, no. 4, pp. 113-115, 2014.

[25] Y. Zhang, T.-Y. Diao, L. Wang, C.-T. Che, and M.-S. Wong, "Protective effects of water fraction of Fructus Ligustri Lucidi extract against hypercalciuria and trabecular bone deterioration in experimentally type 1 diabetic mice," Journal of Ethnopharmacology, vol. 158, pp. 239-245, 2014.

[26] Y. Guo, Y. Li, L. Xue et al., "Salvia miltiorrhiza: an ancient Chinese herbal medicine as a source for anti-osteoporotic drugs," Journal of Ethnopharmacology, vol. 155, no. 3, pp. 14011416, 2014

[27] B. Miao, J. Wang, Y. Zhu, C. Yue, and M. Chen, "Experimental study on effect of Salvia miltiorrhiza on alveolar bone metabolism and variation in bone mass in diabetic rats," China Journal of Chinese Materia Medica, vol. 37, no. 11, pp. 1659-1662, 2012.

[28] X. Chen, Z. Lin, H. Chen, and X. Chen, "The protection of tetramethylpyrazine on bone in diabetic osteoporosis rat," Journal of Putian University, vol. 15, no. 5, pp. 46-49, 2008. 
[29] L. Zhang, H. Ge, and L. Zhao, "Effects of eucommia leaves lavoids on osteoporosis in castrated rat with diabetes melli," Chinese Journal of Gerontology, vol. 23, no. 6, pp. 370-372, 2003.

[30] J. Liang, H. Chen, W. Pan, and C. Xu, "Puerarin inhibits caspase3 expression in osteoblasts of diabetic rats," Molecular Medicine Reports, vol. 5, no. 6, pp. 1419-1422, 2012.

[31] Y. Li, H. Pan, and Y. Liang, "Experiment study on protection of Puerarin in diabetic osteoporosis," Chinese Archives of Traditional Chinese Medicine, vol. 30, no. 4, pp. 848-850, 2012.

[32] L. Pei, "The effect of flavonoids of Aralia echinocaulis HandMazz on bone metabolism in the diabteic rats," in Proceedings of the in 4th International Chinese Medicine and Diabetes Conferences, p. 7, Beijing, China, 2009.

[33] Z. Luo, W. Liang, Z. Luo et al., "Oral administration of quercetin inhibits bone loss in rat model of diabetic osteopenia," European Journal of Pharmacology, vol. 670, no. 1, pp. 317-324, 2011.

[34] C. Pohaci, M. Groza, L. Mareş, M. Ciocoiu, and M. Bădescu, "Beneficial dexa-related effects of natural polyphenols on experimentally-induced diabetes mellitus complications," Revista medico-chirurgicala a Societatii de Medici si Naturalisti din Iasi's, vol. 113, no. 3, pp. 838-844, 2009.

[35] A. N. Shuid, N. Mohamed, I. N. Mohamed et al., "Nigella sativa: a potential antiosteoporotic agent," Evidence-Based Complementary and Alternative Medicine, vol. 2012, Article ID 696230, 6 pages, 2012.

[36] M. F. Altan, "Effects of Nigella sativa and human parathyroid hormone on bone mass and strength in diabetic rats," Biological Trace Element Research, vol. 116, no. 3, pp. 321-328, 2007.

[37] M. F. Altan, M. Kanter, S. Donmez, M. E. Kartal, and S. Buyukbas, "Combination therapy of Nigella sativa and human parathyroid hormone on bone mass, biomechanical behavior and structure in streptozotocin-induced diabetic rats," Acta Histochemica, vol. 109, no. 4, pp. 304-314, 2007.

[38] L. Badescu, O. Badulescu, M. Badescu, and M. Ciocoiu, "Mechanism by Sambucus nigra extract improves bone mineral density in experimental diabetes," Evidence-based Complementary and Alternative Medicine, vol. 2012, Article ID 848269, 6 pages, 2012.

[39] L. Du, L. Yin, M. Chen, and Y. Liu, "Effects of Bushen Zhuanggu capsule on bone mineral metabolism and bone density of rats with diabetes osteoporosis," Chinese Journal of Traditional Medical Science and Technology, vol. 17, no. 4, pp. 293-295, 2010.

[40] D. Jiang, B. Wang, Y. Chen, C. Liu, and Z. Liu, "Research on the effects of Shen-xiaokang on the morphology of osteoporosis in Daibetic Rats," Liao Ning Zhongyi Zazhi, vol. 33, no. 10, pp. $1252-$ 1254, 2006

[41] J. Xu, N. Liang, and Z. Chen, "Research on the effect of bushen jianpi huoxue decoction on bone metabolism in rats due to type 2 diabetes with osteoporosis," Shanxi Journal of TCM, vol. 31, no. 5, pp. 48-50, 2015.

[42] S. Li, M. Xiong, C. Chen et al., "Experimental studies on preventive effect of Shuanghuang Yigu prescription on menopausal diabetses osteoporosis," Traditional Chinese Drug Research and Clinical Pharmacology, vol. 14, no. 5, pp. 296-298, 2003.

[43] Z. Guan, H. Dong, and Q. Dong, "Experimental study on the effect of Tangshukang on the bone metabolism, BMD and bone biomechanics in diabetic osteoporosis rats," Information on Traditional Chinese Medicine, vol. 27, no. 6, pp. 80-82, 2010.

[44] Y. Jiang, Experimental Study on the Effect of Bushen Zhuanggu Capsule on Bone Resorption-Formation Couple Links in Diabetic Osteoporosis Rats, Chengdu University of Chinese Medicine, Chengdu, China, 2002.
[45] Y. Su, H. Xing, L. Zheng, J. Lin, and X. Chen, "Experiment on the effect of QIANGGUBAO on metabolism of bone collagen in the diabetic osteoporosis rats," Chinese Journal of Osteoporosis, vol. 12, no. 3, pp. 289-291, 2006.

[46] I. Takamoto and T. Kadowaki, "Diabetes and osteoporosis," Clinical Calcium, vol. 14, no. 2, pp. 255-261, 2004.

[47] Y. B. Guo, L. L. Wang, R. F. Ma et al., "Etiology, pathology and prospects of TCM in osteoporosis treatment," Modernization of Traditional Chinese Medicine and Materia Medica-World Science and Technology, vol. 17, no. 4, pp. 768-772, 2015.

[48] "Preliminary exploration of the TCM theory 'spleen governs digestion and transportation," Journal of Traditional Chinese Medicine, vol. 2, no. 4, pp. 285-288, 1982.

[49] W.-H. Chen, X.-X. Liu, P.-J. Tong, and H.-S. Zhan, "Diagnosis and management of knee osteoarthritis: Chinese medicine expert consensus (2015)," Chinese Journal of Integrative Medicine, vol. 22, no. 2, pp. 150-153, 2016.

[50] Y. G. Tian, Y. Li, J. S. Li et al., "Effects of therapies for regulating and reinforcing lung and kidney on osteoporosis in rats with chronic obstructive pulmonary disease," Journal of Traditional Chinese Medicine, vol. 35, no. 2, pp. 175-183, 2015.

[51] D. Ju, M. Liu, H. Zhao, and J. Wang, "Mechanisms of 'kidney governing bones' theory in traditional Chinese medicine," Frontiers of Medicine in China, vol. 8, no. 3, pp. 389-393, 2014.

[52] C.-H. Hsu, C.-J. Lee, T.-J. Chien et al., “The relationship between qi deficiency, cancer-related fatigue and quality of life in cancer patients," Journal of Traditional and Complementary Medicine, vol. 2, no. 2, pp. 129-135, 2012.

[53] Z.-Z. Yang, W. Liu, F. Zhang, Z. Li, and Y.-Y. Cheng, "Deciphering the therapeutic mechanisms of Xiao-Ke-An in treatment of type 2 diabetes in mice by a Fangjiomics approach," Acta Pharmacologica Sinica, vol. 36, no. 6, pp. 699-707, 2015.

[54] D. D. Zhao, S. H. Gao, Q. Q. Mu, P. J. Qin, and F. F. Mo, "Theoretical study on treating type 2 diabetes by regulating the liver, spleen and kidney," Chinese Medicine, vol. 55, no. 3, pp. 205-208, 2014.

[55] D.-A. Zhou, Y.-N. Deng, L. Liu, and J.-J. Li, "Effect of kidney-reinforcing and marrow-beneficial traditional Chinese medicine-intervened serum on the proliferation and osteogenic differentiation of bone marrow stromal cells," Experimental and Therapeutic Medicine, vol. 9, no. 1, pp. 191-196, 2015.

[56] K. Su, F. Zhu, L. Guo, Y. Zhu, W. Li, and X. Xiong, "Retrospective study on Professor Zhongying Zhou's experience in Traditional Chinese Medicine treatment on diabetic nephropathy," Journal of Traditional Chinese Medicine, vol. 33, no. 2, pp. 262-267, 2013.

[57] X. Liu, L. Liu, P. Chen et al., "Clinical trials of traditional Chinese medicine in the treatment of diabetic nephropathya systematic review based on a subgroup analysis," Journal of Ethnopharmacology, vol. 151, no. 2, pp. 810-819, 2014.

[58] L. Wang, Y. Li, Y. Guo et al., "Herba Epimedii: an ancient Chinese herbal medicine in the prevention and treatment of osteoporosis," Current Pharmaceutical Design, vol. 22, no. 3, pp. 328-349, 2016.

[59] L. Zhang, Q.-M. Zhang, Y.-G. Wang, D.-L. Yu, and W. Zhang, "The TCM pattern of the six-zang and six-fu organs can be simplified into the pattern of five-zang and one-fu organs," Journal of Traditional Chinese Medicine, vol. 31, no. 2, pp. 147151, 2011.

[60] J. K. Chen, Chinese Medical Herbology and Pharmacology, Art of Medicine Press, Industry, Calif, USA, 2010. 
[61] K. Nakashima, H. Miyashita, H. Yoshimitsu, Y. Fujiwara, R. Nagai, and T. Ikeda, "Two new prenylflavonoids from Epimedii Herba and their inhibitory effects on advanced glycation endproducts," Journal of Natural Medicines, vol. 70, no. 2, pp. 290295, 2016.

[62] W. Yuan, Y. Zhang, Y. Ge, M. Yan, R. Kuang, and X. Zheng, "Astragaloside IV inhibits proliferation and promotes apoptosis in rat vascular smooth muscle cells under high glucose concentration in vitro," Planta Medica, vol. 74, no. 10, pp. 1259-1264, 2008.

[63] S. Raoufi, T. Baluchnejadmojarad, M. Roghani, T. Ghazanfari, F. Khojasteh, and M. Mansouri, "Antidiabetic potential of salvianolic acid B in multiple low-dose streptozotocin-induced diabetes," Pharmaceutical Biology, vol. 53, no. 12, pp. 1803-1809, 2015.

[64] M. Huang, P. Wang, S. Xu et al., "Biological activities of salvianolic acid B from Salvia miltiorrhiza on type 2 diabetes induced by high-fat diet and streptozotocin," Pharmaceutical Biology, vol. 53, no. 7, pp. 1058-1065, 2015.

[65] X. Li, Z. Xu, Z. Jiang et al., "Hypoglycemic effect of catalpol on high-fat diet/streptozotocin-induced diabetic mice by increasing skeletal muscle mitochondrial biogenesis," Acta Biochimica et Biophysica Sinica, vol. 46, no. 9, pp. 738-748, 2013.

[66] M. A. Carai, G. Colombo, B. Loi et al., "Hypoglycemic effects of a standardized extract of Salvia miltiorrhiza roots in rats," Pharmacognosy Magazine, vol. 11, no. 44, supplement 4, pp. S545-S549, 2015.

[67] G. Qiang, X. Yang, L. Shi et al., "Antidiabetic effect of salvianolic acid a on diabetic animal models via AMPK activation and mitochondrial regulation," Cellular Physiology and Biochemistry, vol. 36, no. 1, pp. 395-408, 2015.

[68] T. W. Lau, F. F. Y. Lam, K. M. Lau et al., "Pharmacological investigation on the wound healing effects of Radix Rehmanniae in an animal model of diabetic foot ulcer," Journal of Ethnopharmacology, vol. 123, no. 1, pp. 155-162, 2009.

[69] H. B. Kwak, D. Yang, H. Ha et al., "Tanshinone IIA inhibits osteoclast differentiation through down-regulation of c-Fos and NFATcl," Experimental and Molecular Medicine, vol. 38, no. 3, pp. 256-264, 2006.

[70] L. Wang, Y. Li, Y. Guo et al., "Herba epimedii: an ancient Chinese herbal medicine in the prevention and treatment of osteoporosis," Current Pharmaceutical Design, vol. 22, no. 3, pp. 328-349, 2015.

[71] Q. Bian, J.-H. Huang, Q.-Q. Liang et al., “The osteogenetic effect of astragaloside IV with centrifugating pressure on the OCT-1 cells," Pharmazie, vol. 66, no. 1, pp. 63-68, 2011.

[72] Q. Li, Y.-S. Fan, Z.-Q. Gao, K. Fan, and Z.-J. Liu, "Effect of Fructus Ligustri Lucidi on osteoblastic like cell-line MC3T3-E1," Journal of Ethnopharmacology, vol. 170, pp. 88-95, 2015.

[73] L. Wang, J. Zhang, Y. Hong, Y. Feng, M. Chen, and Y. Wang, "Phytochemical and pharmacological review of da Chuanxiong formula: a famous herb pair composed of chuanxiong rhizoma and gastrodiae rhizoma for headache," Evidence-based Complementary and Alternative Medicine, vol. 2013, Article ID 425369, 16 pages, 2013.

[74] Y. Zhang, H. Zhang, F. Wang, D. Yang, K. Ding, and J. Fan, "The ethanol extract of Eucommia ulmoides Oliv. leaves inhibits disaccharidase and glucose transport in Caco-2 cells," Journal of Ethnopharmacology, vol. 163, pp. 99-105, 2015.

[75] C.-Y. Su, Q.-L. Ming, K. Rahman, T. Han, and L.-P. Qin, "Salvia miltiorrhiza: traditional medicinal uses, chemistry, and pharmacology," Chinese Journal of Natural Medicines, vol. 13, no. 3, pp. 163-182, 2015.

[76] W. Xie, Y. Zhao, and L. Du, "Emerging approaches of traditional Chinese medicine formulas for the treatment of hyperlipidemia," Journal of Ethnopharmacology, vol. 140, no. 2, pp. 345367, 2012.

[77] Y. Li, H. Pan, and Y. Liang, "Experimental study on the effect of puerarin injection in high glucose treated osteoblast," Chinese Journal of Traditional Medical Science and Technology, vol. 19, no. 4, pp. 318-319, 2012.

[78] X. Yin, L. Li, L.-L. Zheng et al., "Influence of aqueous extract of Aralia echinocaulis Hand.-Mazz on the expression of fracture healing-related factor receptors," Zhongguo Gu Shang, vol. 24, no. 9, pp. 761-765, 2011.

[79] O. Coskun, M. Kanter, A. Korkmaz, and S. Oter, "Quercetin, a flavonoid antioxidant, prevents and protects streptozotocininduced oxidative stress and $\beta$-cell damage in rat pancreas," Pharmacological Research, vol. 51, no. 2, pp. 117-123, 2005.

[80] J. Sun and S. Yu, "Research progress of $\mathrm{n}$ pharmacological action of quercetin," Chinese Medicines Journal of Research and Practice, vol. 25, no. 3, pp. 85-88.

[81] M. Luo, D. Luo, and W. Zhao, "Research progress on pharmacological action of quercetiin," Chinese Journal of Ethnomedicine and Ethnopharmacy, vol. 25, no. 17, pp. 12-14, 2014.

[82] A. Teixeira, N. Baenas, R. Dominguez-Perles et al., "Natural bioactive compounds from winery by-products as health promoters: a review," International Journal of Molecular Sciences, vol. 15, no. 9, pp. 15638-15678, 2014.

[83] Z. Guan and Q. Dong, "Study of the effect of Tangshukang for the VDR, TGF- $\beta 1$, CaBp-D9K mRNA expression on the diabetic osteoporosis rats," Modern Medicine Journal of China, vol. 12, no. 4, pp. 4-6, 2010.

[84] H. Xing, An Experimental Study on the Effect of Qianggubao on the Metabolism of Bone Collagen in Diabetic Osteoporosis Rats, Chinese Internal Medicine, Fujian College of TCM, 2005.

[85] X. Yang, A. J. Mostafa, M. Appleford, L. W. Sun, and X. Wang, "Bone formation is affected by matrix advanced glycation end products (AGEs) in vivo," Calcified Tissue International, 2016.

[86] V. Huovinen, V. Saunavaara, R. Kiviranta et al., "Vertebral bone marrow glucose uptake is inversely associated with bone marrow fat in diabetic and healthy pigs: $\left[{ }^{18} \mathrm{~F}\right] \mathrm{FDG}-\mathrm{PET}$ and MRI study," Bone, vol. 61, pp. 33-38, 2014.

[87] A. Y. Leung, “Traditional toxicity documentation of Chinese materia medica-an overview," Toxicologic Pathology, vol. 34, no. 4, pp. 319-326, 2006.

[88] P. M. Le, A. Benhaddou-Andaloussi, A. Elimadi, A. Settaf, Y. Cherrah, and P. S. Haddad, "The petroleum ether extract of Nigella sativa exerts lipid-lowering and insulin-sensitizing actions in the rat," Journal of Ethnopharmacology, vol. 94, no. 2-3, pp. 251-259, 2004.

[89] U. Kalus, A. Pruss, J. Bystron et al., "Effect of Nigella sativa (black seed) on subjective feeling in patients with allergic diseases," Phytotherapy Research, vol. 17, no. 10, pp. 1209-1214, 2003.

[90] A. K. Maji, S. Pandit, P. Banerji, and D. Banerjee, "Pueraria tuberosa: a review on its phytochemical and therapeutic potential," Natural Product Research, vol. 28, no. 23, pp. 2111-2127, 2014.

[91] N. Santosh, K. Mohan, S. Royana, and T. B. Yamini, "Hepatotoxicity of tubers of Indian Kudzu (Pueraria tuberosa) in rats," Food and Chemical Toxicology, vol. 48, no. 4, pp. 1066-1071, 2010. 
[92] Y. Zhou, X. Su, B. Cheng, J. Jiang, and H. Chen, "Comparative study on pharmacological effects of various species of Pueraria," Zhongguo Zhongyao Zazhi, vol. 20, no. 10, pp. 619-621, 1995.

[93] Z. Zhang, T.-N. Lam, and Z. Zuo, "Radix puerariae: an overview of its chemistry, pharmacology, pharmacokinetics, and clinical use," Journal of Clinical Pharmacology, vol. 53, no. 8, pp. 787-811, 2013.

[94] S.-Y. Yu, H.-T. OuYang, J.-Y. Yang et al., "Subchronic toxicity studies of Radix Astragali extract in rats and dogs," Journal of Ethnopharmacology, vol. 110, no. 2, pp. 352-355, 2007.

[95] W. Y. W. Lee, L. C. M. Chiu, and J. H. K. Yeung, "Cytotoxicity of major tanshinones isolated from Danshen (Salvia miltiorrhiza) on HepG2 cells in relation to glutathione perturbation," Food and Chemical Toxicology, vol. 46, no. 1, pp. 328-338, 2008.

[96] M. Xu, M. Zhang, H. E. Yao, L. Chen, and X. Xie, "Study on the toxic effect of the liposoluble components of Salvia on rat retinal Müller cells," West China Journal of Pharmaceutical Sciences, vol. 28, no. 5, pp. 453-455, 2013.

[97] C. Hu, Y. Huang, X. Wang, C. Sun, T. Luo, and X. Yang, "A toxicity comparative study of eucommia ulmoides seed and bark," Journal of Jinggangshan University (Natural Science), vol. 36, no. 1, pp. 95-100, 2015.

[98] J. Zhang, H. Du, Q. Li, and Y. Ding, "Study advancement about pharmacological andtoxicological of Eucommia ulmoides Oliv," Journal of Henan University (Medical Science), vol. 33, no. 3, pp. 217-222, 2014. 


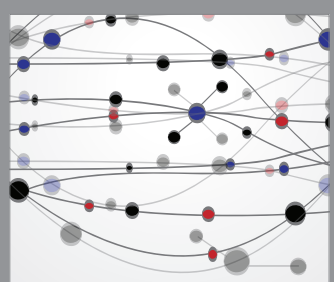

The Scientific World Journal
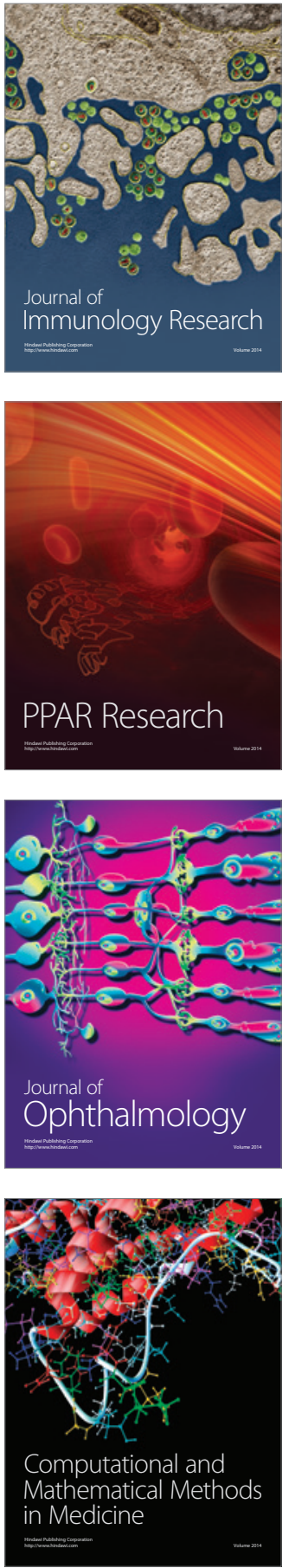

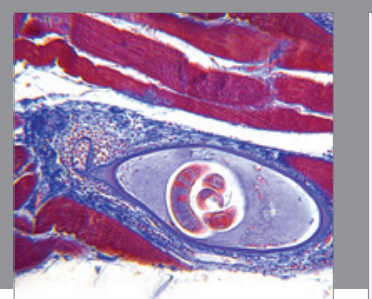

Gastroenterology Research and Practice

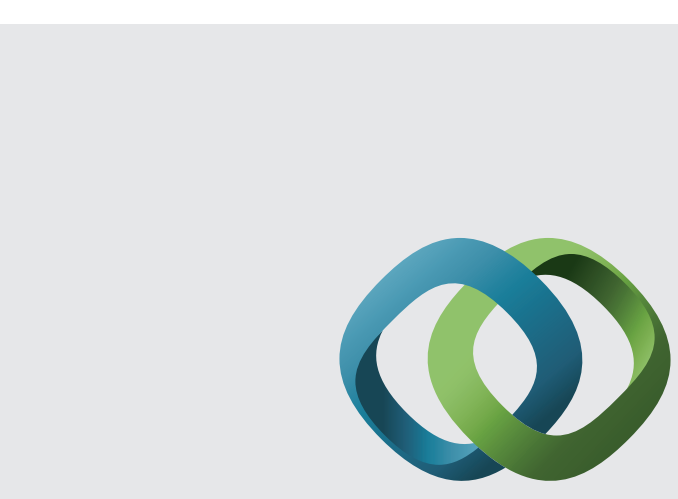

\section{Hindawi}

Submit your manuscripts at

http://www.hindawi.com
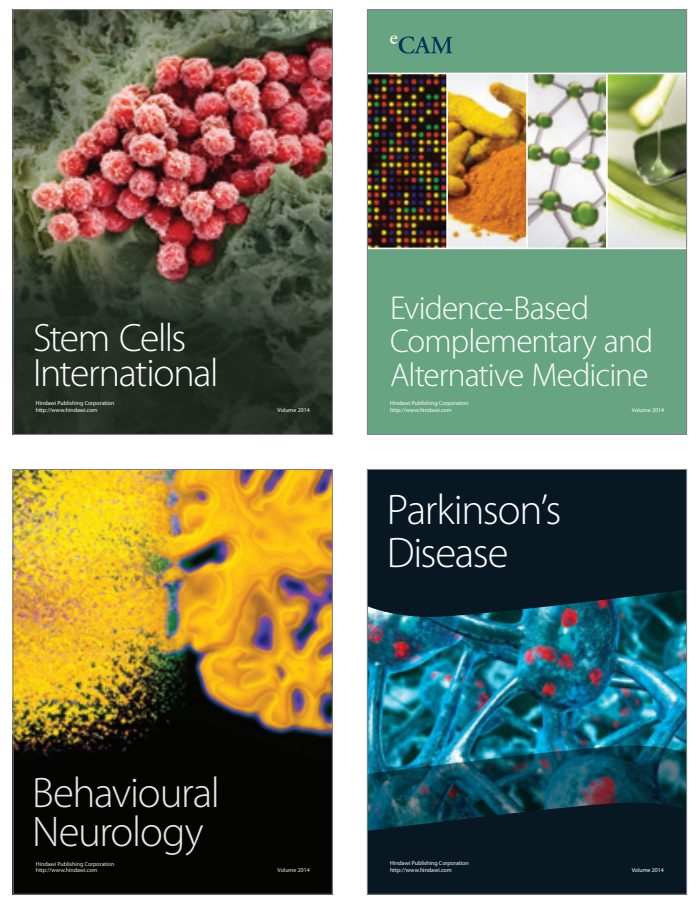
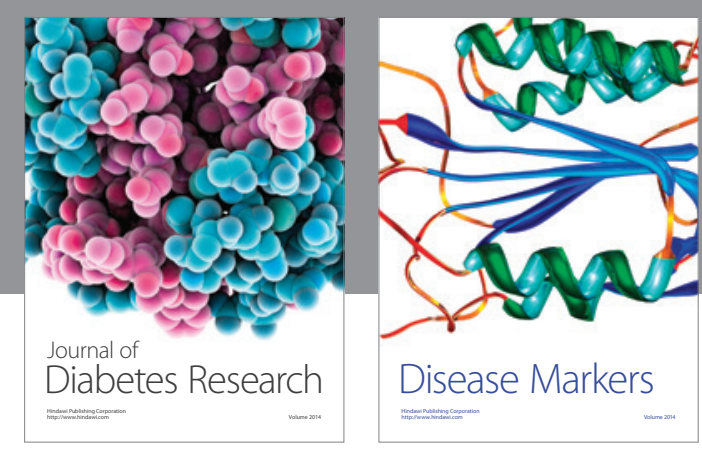

Disease Markers
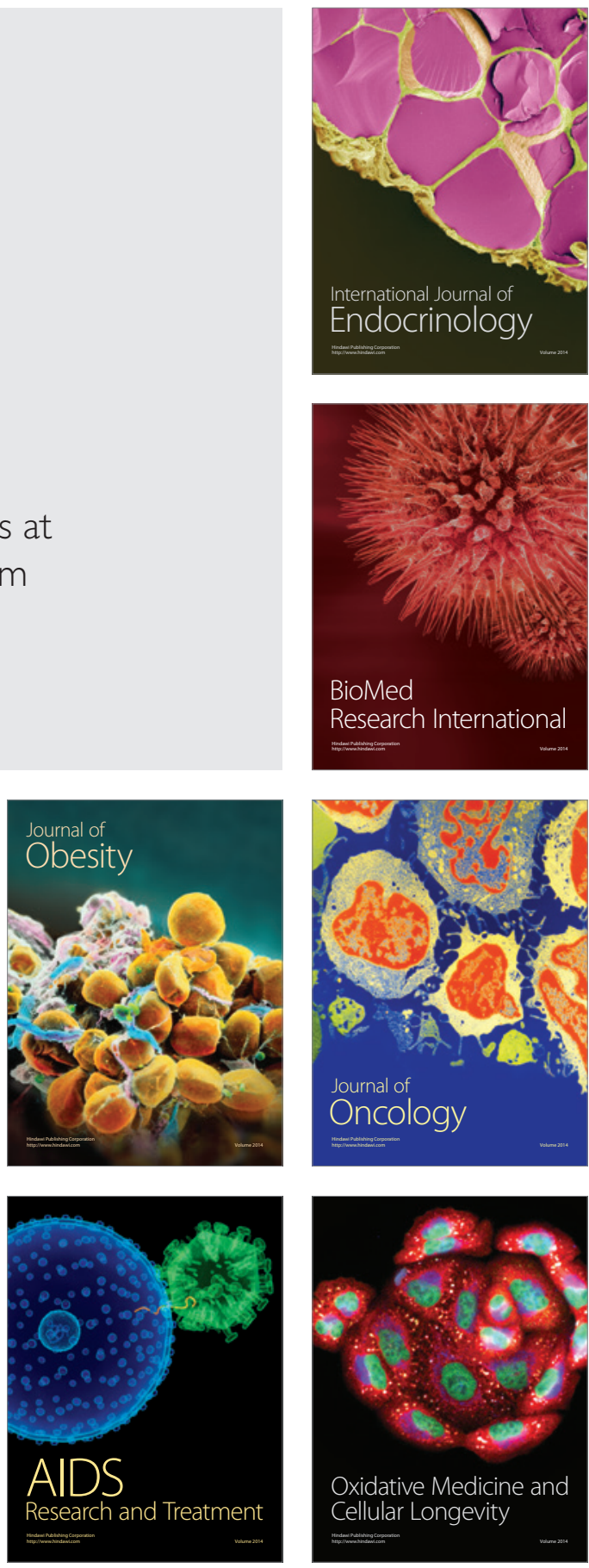